\title{
(P) MDB: DE REBELDE A STATUS QUO
}

\section{Paulo Victor Teixeira Pereira de Melo ${ }^{1}$}

Resumo: Os partidos políticos são instituições de extrema relevância em um sistema democrático representativo, isto porque é exatamente através deles que se dá a vocalização dos cidadãos no sistema político, tendo a função de canalizar e expressar interesses reivindicações sociais. São os responsáveis nas democracias contemporâneas por organizar as disputas e o espaço político. Entretanto, existem poucos estudos sobre os partidos brasileiros do atual período democrático, sabedor dessa deficiência, realizo neste artigo o estudo do Partido do Movimento Democrático Brasileiro (PMDB), no que tange a sua trajetória e o peso do seu apoio no atual jogo político eleitoral.

Palavras-Chave: Partidos Políticos, PMDB, Competição Eleitoral.

Resumen: Los partidos políticos son instituciones de gran relevancia en un sistema democrático representativo, porque es precisamente a través de ellos que le da la vocalización de los ciudadanos en el sistema político para actuar como un canal para expresar sus intereses y demandas sociales. Ellos son responsables de la organización en los conflictos las democracias contemporáneas y el espacio político. Sin embargo, hay pocos estudios sobre los partidos brasileños del actual período democrático, conscientes de esta deficiencia, me doy cuenta de este artículo, el estudio del Partido del Movimiento Democrático Brasileño (PMDB), con respecto a su trayectoria y el peso de su apoyo en el juego electoral político actual.

Palabras-clave: Partidos Políticos, PMDB, Competencia Electoral.

Abstract: Political parties are extremely relevant institutions on the context of a representative democratic system, precisely because they are responsible for the vocalization of citizens in the political system, channeling and expressing interests and social claims. They are responsible for organizing the disputes and political space in modern democracies. There are, however, few studies concerning Brazilian political parties of the current democratic period. With that in mind, this article performs a brief study on the Democratic Movement Party of Brazil (PMDB), in what concerns its trajectory an the importance of it's support on the current electoral game.

Key-words: Political Parties, PMDB, Electoral Competition.

${ }^{1}$ Universidade Federal de Minas Gerais (UFMG). E-mail: paulovictormelo@gmail.com. 


\section{INTRODUÇÃo}

Que os partidos políticos são partes essenciais do sistema político a literatura é clara. Eles são os responsáveis por mobilizar o eleitorado, organizar a competição política, tem a função de canalizar e expressar interesses reivindicações sociais, organizar o processo legislativo e constituir os governos. Temos também, como ponto importante apresentado por Sartori (1976), conclui-se que a existência dos partidos somente é possível com a existência de algum tipo eleição. Downs (1999) ressalta que os partidos são "maquinas de conquista de votos", tendo sempre a mente estratégias para maximizar as suas chances de sucesso eleitoral. No entanto, qual o real peso dos partidos brasileiros na conquista dos votos? Qual a eficiência destes partidos em conversão de candidatos em cadeiras?

No entanto, sabemos que nem todos partidos "trabalham" no sentido de maximizarem o seu número de cadeiras. A literatura sobre partidos mostra que temos partidos que vão buscar nas eleições buscarem a defesa de políticas, de cargos e de votos o que deixa cada partido livre na para analisar e decidir pela melhor estratégia. $\mathrm{O}$ partido que vamos analisar nesse trabalho inclusive tem nos seus primórdios uma defesa clara de política e com o passar do tempo ele vai se "adaptando" as conjecturas que lhe são apresentadas.

Para tentar trazer luz a alguns das perguntas que levantamos anteriormente, vamos realizar a analise de um dos principais partidos no sistema político brasileiro, o Partido do Movimento Democrático Brasileiro (PMDB). O PMDB é detentor de uma origem que remete ao MDB (Movimento Democrático Brasileiro), que era oficialmente o partido de oposição ao Regime Militar de 1964 a 1985 e hoje é considerado o maior partido do país, devido a sua capilarização, bancadas federais e número de prefeituras. Assumindo no atual cenário político brasileiro crucial importância, sendo convidado a compor os vários governos, independente do seu posicionamento durante a disputa pelo cargo.

Para melhor elucidar a atual força do PMDB temos de partir dos tempos que ele era a vocalização da oposição brasileira. Para isso vamos traçar um histórico do partido que vai permitir traçar o caminho percorrido pelo partido para sair do "rebelde" até tornar-se o status quo do sistema político brasileiro. Em sequência faremos uma analise mais profunda da maquina partidária que é o PMDB atualmente, com base nos dados eleitorais de 2010. 


\section{HISTÓRICO DO (P) MDB}

A literatura sobre partidos políticos trata de três abordagens para o surgimento de partidos políticos a sociológica, a institucional e a racional. Apresentadas sinteticamente por Lipset e Rokken (1967), Duverger (1980) e Downs (1999) respectivamente. Estas abordagens podem ser resumidas seguinte forma: a abordagem sociológica defende que os partidos surgem por representarem expressões de conflitos sociais; a institucional que aponta o surgimento dos partidos se dá por atos institucionais, ou seja, se dá por dentro das instituições vigentes; e finalmente, a abordagem racional ou competitiva delimita que os partidos são criados para que os políticos alcancem seus objetivos, ou seja, a conquista dos votos. Sabendo dessas clivagens que a literatura coloca como as responsáveis pelo surgimento dos partidos políticos, me pergunto qual dessas melhor explicaria o surgimento do (P) MDB? Para responder essa indagação é necessário revisar um pouco da história política brasileira.

Retrocedendo a 1964, o Brasil vivia um momento de grande instabilidade política, que decorria de alguns atos que o precedem. No dia primeiro de janeiro de 1961, o Presidente Juscelino Kubitscheck dá posse ao candidato eleito Jânio Quadros, apresentando assim o maior período de democracia representativa no Brasil. Após sete meses de extrema dificuldade junto ao Congresso Nacional, o presidente renuncia ao cargo, gerando assim um momento de vacância de poder dado que o seu vice João Goulart estava em missão oficial para o Oriente. Assume assim a Presidência interinamente o presidente da Câmara dos Deputados, Ranieri Mazzilli. Informado e aconselhado pelo seu cunhado e governador do Rio Grande do Sul, Leonel Brizola, o Vice-Presidente João Goulart volta ao Brasil pelo Uruguai e começa o movimento para que ele possa assumir a presidência. No entanto, o seu nome sofria de oposições devido ao fato de ser considerado bastante ligado a setores de esquerda e comunista.

Com base em um arranjo parlamentarista pensado pelo deputado mineiro Tancredo Neves, o presidente João Goulart toma posse sob suspeita. Todavia, no início do ano de 1963 é realizado um plebiscito que põe fim a experiência parlamentarista brasileira devolvendo totais poderes ao presidente da republica. Livre das "amarras" do antigo sistema de governo, João Goulart podia colocar em prática as suas agendas de governo, o que envolvia uma boa parte das intituladas "reformas de bases". A situação política e social do país era de ebulição, com intensos debates entre setores mais conservadores e os que apoiavam as decisões do presidente. $\mathrm{O}$ auge dessas manifestações pró e contras foi o comício, proferido pelo presidente na Praça da República, Rio de Janeiro em 13 de março de 1964 e a Marcha da Família com Deus pela Liberdade, São Paulo 19 de março do mesmo ano. Com base nessa grande 
efervescência política e social na madrugada do dia 31 de março de 1964, tropas comandadas pelo General Olympio Mourão Filho comandante da $4^{\circ}$ Região Militar, marcha de Juiz de Fora, MG com destina a Capital Federal e consegue em quarenta e oito horas destituir a $4^{\circ}$ Republica Brasileira. Tenho de deixar claro que esse movimento de dissolução do sistema vigente encontra respaldo em partes da sociedade civil e de governantes como o Governador de Minas Gerais Magalhães Pinto e do Estado da Guanabara Carlos Lacerda. O presidente da Câmara Ranieri Mazzili, volta ocupar o cargo de Presidente da Republica, no entanto sob o "governo dos ministros das forças armadas”. Essa situação perdura até dia 09 de abril quando é editado o Ato Institucional $\mathrm{n}^{\circ} 1$ que retira o presidente do seu cargo e nomeia o Marechal do Exercito Humberto de Alencar Castelo Branco, presidente incumbido de dentro de alguns meses convocar novas eleições para retornar o país à normalidade democrática, fato que todos sabemos não foi realizado e "mergulhou" o país em um período autoritário de 20 anos.

Em outubro de 1965 foram realizadas eleições para governos de estados, na qual, o governo central sofreu derrotas nos, importantes, estados como Minas Gerais e Rio de Janeiro. O que não foi bem acolhido por setores mais "linha dura" do regime, levando a publicação do Ato Institucional $\mathrm{n}^{\circ}$ 2, que dentre as suas medidas destituía os partidos políticos existentes, instituía a eleição indireta para a presidência da República e dava ao executivo nacional poder de cassação e decretação de estado de sitio sem autorização previa do Congresso. Logo após é "baixado" o Ato Institucional no 3 que institui eleições indiretas também para os governadores de estados.

O somatório dos $\mathrm{AI} 2$ e $\mathrm{AI} 3$ levou a queda na simpatia inicial dada ao denominado pelos militares de "Revolução Democrática". Fazendo que os militares perdessem apoios importantes na classe civil e política vigente. Sabendo disso, o Regime decreta o Ato Institucional $\mathrm{n}^{\circ} 4$ que institui a o sistema bipartidário no país. $\mathrm{O}$ $\mathrm{AI}_{4}$ "determinava que a criação de novas organizações políticas, tarefa a ser realizada pelos membros do Congresso em quarenta e cinco dias, exigiria o apoio de um terço dos deputados federais e um terço dos senadores. Este requisito, no entanto, não significava que a intenção fosse à criação de um sistema de três partidos, Na verdade, implicava a possibilidade de se estabelecer uma maioria de dois terços a favor do governo, formando-se com os parlamentares restantes uma oposição simbólica.” (Kinzo, 1988)

Após a exposição que levou a instituição do bipartidarismo no Brasil e a fundação do precursor do objeto aqui estudado, o (P) MDB, posso me ater mais detalhadamente ao partido e as suas configurações. Respondendo a nossa primeira indagação, acredito que podemos aplicar ao caso do (P) MDB a seguinte explicação teórica: a de ser uma fundação institucional "de cima para baixo". Afirmação que 
encontramos respaldo em Kinzo (1988) quando ela descreve como foram formados os diretórios nacionais e subnacionais do movimento que acabava de ser criado: "Tendo sido criado por parlamentares, à organização do MDB obviamente foi montada de cima para baixo. Quando a sua criação constituiu-se um diretório provisório, que integrou todos os parlamentares que assinaram o manifesto de fundação do partido. Estes parlamentares foram os mesmos que, com a ajuda de deputados estatuais que se filiaram ao MDB, se incumbiram de formar diretórios regionais em seus respectivos Estados.”

Em relação às características dos filiados aos novos "partidos" criados, recorrendo novamente a Kinzo encontro a seguinte citação que bem descreve a situação ideológica dos novos partidos: “A diversidade de origens partidárias que caracterizou a ARENA e o MDB, não apenas era uma conseqüência natural do modo artificial pelo qual foi estabelecido o bipartidarismo, mas também refletia a falta de clareza ideológica e representativa dos antigos partidos políticos." Essa descrição da autora deve ser analisada com a tabela que mostra a origem dos parlamentares que formaram as novas organizações.

Tabela 1: Filiação à ARENA e ao MDB dos membros dos antigos partidos na Câmara dos Deputados, 1966

\begin{tabular}{|l|c|c|c|}
\hline \multicolumn{1}{|c|}{ Partidos Antigos } & \multicolumn{3}{c|}{ Novos Partidos } \\
\cline { 2 - 4 } & ARENA & MDB & TOTAL \\
\hline UDN (União Democrática Nacional) & & & \\
\hline PSD (Partido Social Democrático) & 86 & 9 & 95 \\
\hline PSP (Partido Social Progressista) & 78 & 43 & 121 \\
\hline PR (Partido Republicano) & 18 & 2 & 20 \\
\hline PL (Partido Libertador) & 4 & & 4 \\
\hline PRP (Partido da Representação Popular) & 3 & & 3 \\
\hline Trabalhistas/Reformistas & 5 & & 5 \\
\hline PTB (Partido Trabalhista Brasileiro) & 38 & 78 & 116 \\
\hline PDC (Partido Democrata Cristão) & 13 & 6 & 19 \\
\hline PTN (Partido Trabalhista Nacional) & 8 & 4 & 12 \\
\hline PST (Partido Social Trabalhista) & 2 & & 2 \\
\hline PRT (Partido Republicano Trabalhista) & 2 & 2 & 4 \\
\hline MTR (Movimento de Renovação Trabalhista) & & 3 & 3 \\
\hline PSB (Partido Socialista Brasileiro) & & 2 & 2 \\
\hline Não Filiados & & & 3 \\
\hline TOTAL & & 149 & 409 \\
\hline FOnte: Kinzo, & & \\
\hline
\end{tabular}

Fonte: Kinzo, 1988. p. 32.

Analisando com maior detalhe os dados temos que a maioria dos deputados (78\%) que eram filiados aos partidos considerados pela autora como conservadores 
foram para a base da ARENA e o restante (22\%) se filiaram ao MDB. Os Deputados que faziam parte dos partidos denominados trabalhistas/reformistas foram em sua maioria (60\%) para o MDB e o restante se filiou a ARENA (40\%). No entanto, ao se olhar apenas para a base que compõe o novo MDB temos um percentual de $36 \%$ que tem sua origem nos partidos conservadores tendo esses componentes, grande importância devido a como foi realizado o processo de estruturação do partido, sublinhado anteriormente. A maior clivagem que podemos considerar "unificadora" dessa nova organização é a de ser oposição ao regime vigente.

Assim, servindo, por um lado, de principal expressão organizacional da oposição liberal ao regima, o MDB pôde também, aos poucos, atrair a lealdade dos setores populares urbanos e atuar como denominador comum simbólico capaz de absorver or orfãos não só do antigo PTB, mas também do populismo paulista e dos demais partidos e movimentos que se dirigiam a tais setores. (REIS, 2002)

Passado esse período de constituição do partido o mesmo se lança a disputa eleitoral $^{2}$, não alcançado um grande êxito devido ao poder da maquina e do partido da situação do governo. Dado que, como ressaltei acima, a maior parte da estrutura e dos diretórios, principalmente os municipais, ficaram para a ARENA. Restando ao MDB iniciar um processo de constituição do partido, sobretudo nas cidades menos urbanizadas.

\begin{abstract}
"Em 1970 houve eleições municipais em 1897 cidades, e o MDB concorreu em apenas $43 \%$ desse total (816 municípios). Essa disputa marcou o ponto culminante do predomínio arenista: o partido ficou com $87 \%$ das cadeiras do Senado, $71 \%$ na Câmara dos Deputados e 70.6\% nas Assembléias Legislativas. (...) A frogosa derrota sofrida nas eleições de 1970 levou as lideranças emedebistas a buscarem a expansão da estrutura organizacional do partido, privilegiando a construção de uma ampla rede de diretórios locais." (Ferreira e Ribeiro, 2009)
\end{abstract}

Com essa expansão da estrutura partidária e com o aumento do grau de insatisfação da sociedade com o regime, o MDB foi acumulando forças e capital político que o credenciava para, as futuras disputas políticas e eleitorais. Fato que veio a ocorrer nas eleições de 1974, onde o MDB alcançou a consideração da sua capilaridade e foi favorecido por eleições que transcorreram de forma que propíciou um maior debate 3 , podendo assim a organização se apresentar a todo o eleitorado como o membro institucionalizado de oposição ao regime. Tendo assumido após o processo eleitoral

\footnotetext{
2 Temos de apontar que as eleições nessa época eram apenas para deputados (federais e subnacionais), senadores, prefeituras que não eram consideradas áreas de segurança nacional (como as capitais de estados) e vereadores;

3 Em 1974 o General Ernesto Geisel assume a Presidência da República e inicia o processo de distensão do governo ditatorial com o intuito de devolver o país o Estado Democrático de Direito;
} 
força não antes imaginada, impulsionada pelas regiões consideradas mais industrializadas - sul e sudeste - e pelas capitais e maiores cidades que constituíam o maior foco de oposição ao regime.

Após essa "derrota" eleitoral e prevendo uma derrota maior ainda nas eleições de 1978 - devido à forte participação da nova e forte bancada do MDB, que pode assim expor em maior "dimensão" a sua posição de oposição e defensora da democracia e pelas vitorias alcançadas nas eleições municipais de 1976 - o Regime "reage" decretando em 1977 o denominado "Pacote de Abril". Entre as medidas contidas nesse "pacote de medidas", estavam a que decretava o fechamento do Congresso Nacional, instituía existência do Senador Biônico ${ }^{4}$ e retrocedia a abertura do debate livre durante as eleições. Com isso, o regime volta a assumir a maioria absoluta das duas câmaras no Congresso Nacional.

Em Março de 1979, assume a presidência o General Figueiredo que se mantém disposto a dar continuidade à distensão política iniciada por Geisel, que deveria ser "lenta e segura". Para isso, e para conter a força assumida pelo MDB, o governo manda para o Congresso em 19 de outubro de 1979 algumas modificações à "Lei Orgânica dos Partidos Políticos". O Projeto de Lei $\mathrm{n}^{\circ} 37$ propunha o fim dos partidos existentes naquele momento e a volta do país ao pluripartidarismo. O que gerou um grande número de protestos das lideranças do MDB intitulada "Não a Cassação do MDB".

\begin{abstract}
"A mitologia dos mentores do regime se viu desmentida em aspectos importantes pela trajetória do MDB. Um desses aspectos é o que pretendia ver no apoio eleitoral aos partidos e movimentos de cunho popular o mero resultado da engabelação de massas eleitorais amorfas por parte de lideranças espúrias. Excluídas, presumivelmente, tais lideranças, "esclarecido" o público através de esforços doutrinários e propagandísticos de diversos tipos, a afirmação eleitoral do MDB deixou patente que há algo mais consistente em jogo no processo político brasileiro e frustrou as esperanças de que o bipartidarismo imposto viesse a ser o arcabouço da aquiescência popular ao regime. Não admira, portanto, que o governo seja agora o promotor do multipartidarismo e eventualmente da extinção dos partidos existentes." (REIS, 2002)
\end{abstract}

Aprovada em 20 de dezembro de 1979 e sancionada em 20 de dezembro de 1979, a Lei $n^{\circ}$ 6.767, encerrava assim o período bipartidário no Brasil. Forjando um novo sistema que teve a maior parte dos componentes da antiga Arena, formado o “novo" partido PDS, enquanto o MDB se dividiu em quatro novos partidos PMDB, PP, PTB e PDT - o PP após algum tempo foi instinto e reincorporado pelo PMDB5. O

\footnotetext{
4 Um terço do senado passaria a ser eleito de forma indireta. Essa indicação estaria a cargo das Assembléias estaduais;

5 Para maiores detalhes sobre a trajetória dos partidos políticos brasileiros pós período ditatorial consultar (Kinzo, 2001)
} 
PMDB foi então fundado após uma reunião dos senadores, deputados e membros do extinto MDB no dia 15 de Janeiro de 1980 e obtém o seu registro junto ao Tribunal Superior Eleitoral no dia 9 de Junho de 1980 tendo como presidente o Deputado Ulysses Guimarães.

Após a sua constituição como partido lidera como a voz "institucional" dentro regime, a campanha pela volta à democracia e passando pela eleição direta para a presidência da republica em 1985. Demanda que não é alcançada devida há permanência da força do regime dentro do Congresso Nacional. No entanto, sai vencedor do Colégio Eleitoral elegendo Deputado Tancredo Neves como presidente da republica. Infelizmente Tancredo morre antes de assumir a presidência deixando o cargo para o seu vice José Sarney ex-integrante da ARENA.

Analisando os dados eleitorais, número de cadeiras, nas eleições de 1982 2008 podemos confirmar a importância que esse partido assume no sistema político partidário brasileiro, seja como o membro institucional que expressou a voz destoante ao regime autoritário à atual estágio de partido que dá sustentação a grande parte dos governos. O PMDB na primeira eleição pós-redemocratização, já mostra como a imagem de ser um dos propulsores da "volta" a democracia foi favorável a ele, conseguindo a maioria das cadeiras colocadas em disputa.

Tabela 2: Percentual de cadeiras e cargos executivos conquistados pelo PMDB (1982-2008)

\begin{tabular}{|l|r|r|r|r|r|r|r|r|r|r|r|r|r|r|}
\hline & $\mathbf{8 2}$ & $\mathbf{8 5}$ & $\mathbf{8 6}$ & $\mathbf{8 8}$ & $\mathbf{9 0}$ & $\mathbf{9 2}$ & $\mathbf{9 4}$ & $\mathbf{9 6}$ & $\mathbf{9 8}$ & $\mathbf{0 0}$ & $\mathbf{0 2}$ & $\mathbf{0 4}$ & $\mathbf{0 6}$ & $\mathbf{0 8}$ \\
\hline $\begin{array}{l}\text { Senado } \\
\text { Federal }\end{array}$ & 36 & & 77,6 & & 25,8 & & 25,9 & & 44,4 & & 16,7 & & 14,8 & \\
\hline $\begin{array}{l}\text { Câmara dos } \\
\text { Deputados }\end{array}$ & 41,8 & & 53,4 & & 21,5 & & 20,9 & & 16,2 & & 14,4 & & 17,3 & \\
\hline $\begin{array}{l}\text { Governos } \\
\text { Estatuais }\end{array}$ & 40,9 & & 95,7 & & 29,6 & & 33,3 & & 22,2 & & 18,5 & & 25,9 & \\
\hline $\begin{array}{l}\text { Assembléias } \\
\text { Prefeituras }\end{array}$ & 42,7 & & 46,9 & & 20 & & 19,6 & & 16,6 & & 12,5 & & 15,5 & \\
\hline
\end{tabular}

Fonte: FERREIRA e RIBEIRO (2009). P. 59.

Com a expansão do sistema partidário, o partido entra em uma trajetória de descendente no seu sucesso eleitoral e na sua posterior transformação em cadeiras ou cargos executivos. No entanto, o partido ainda não perdeu o seu posto de maior partido do país, dado que ainda possuí o maior número de senadores, deputados, governadores e prefeitos dentro do sistema político brasileiro. E não se pode duvidar da capacidade de restabelecimento dessa importante maquina partidária, como podemos comprovar ao analisar que o partido após a queda alcançada nas eleições de 2002 - 2004 apresenta um crescimento em quase todas as esferas nas eleições posteriores (2004 - 2008), com a sua bancada no Senado Federal a única a destoar desse crescimento. Um partido que 
possui um grau de capilaridade e de presença em todos os municípios do país não pode ser considerado em processo de declínio, pelo contrario acredito que um estudo aprofundado desse partido se mostra cada vez mais necessário.

Acreditamos aqui ser necessária uma melhor elucidação sobre a conexão entre o crescimento eleitoral do (P) MDB e a identificação do eleitorado pelo partido. No inicio do Movimento o partido possuía uma bandeira clara, a defesa da volta à democracia, o que facilitava a sua identificação pelo eleitorado. Essa identificação é um dos fatores responsáveis pelo seu crescimento, partindo dos centros mais industrializados para o interior. Com o passar do tempo e tendo alcançado o seu "objetivo" inicial de voltar o país à democracia, o partido enfrenta uma crise de identificação interna com a falta de um objetivo que unificasse as suas bases o que refletiu no seu eleitorado. O partido optou por atender as demandas regionais dos seus componentes, favorecendo assim a identificação do eleitorado com esses expoentes locais, em deterioração da imagem do partido como um todo. O que impossibilita a construção de uma candidatura a Presidência da República.

No PMDB, a capacidade de articular um projeto político havia deixado de existir desde o período da transição e as condições para uma ação unitária deterioraram-se de forma evidente - desde então a legenda manteve-se como um agregado de interesses regionais precariamente unificados pela maximização de cargos no plano federal. O partido abandonou a pretensão de disputar a presidência, definiu como prioritária a arena estadual e passou a jogar o jogo presidencial valendo-se do aninhamento das disputas eleitorais e do caráter coalizional do presidencialismo. (Melo, 2010)

Acreditamos nessa seção ter deixado claro a historia de fundação e trajetória do partido político que é o objeto de estudo desse trabalho. Conhecer a trajetória das instituições é essencial para reconhecer a sua atual configuração e relevância. Na próxima parte vamos nos dedicar a analisar a atual maquina partidária e como está atuou na eleição de 2010.

\section{O PMDB E A SUA ATUAL RELEVÂNCIA NO CENÁRIO ATUAL}

Começamos esse trabalho com estas duas indagações: Qual o real peso dos partidos brasileiros na conquista dos votos? Qual a eficiência destes partidos em conversão de candidatos em cadeiras? Pretendemos agora com analise dos dados da eleição de 2010 apresentarmos alguns caminhos que possibilitem trazer luz a esses questionamentos. Para isso vamos descrever a atual "maquina" partidária do PMDB. O partido possui um dos maiores, se não o maior, nível de enraizamento entre os partidos brasileiros, o que pode ser expresso pela existência de diretórios municipais em todos 
os municípios brasileiros. Outro dado relevante sobre o tamanho do PMDB é o seu número de filiados, este é o maior entre os partidos brasileiros como ser observado na tabela a baixo

Tabela 3: Número de Filados por partido em julho de 2010

\begin{tabular}{|l|c|c|}
\hline PARTIDO & ELEITORES & $\%$ \\
\hline PMDB & 2316705 & 16,70 \\
\hline PT & 1393890 & 10,05 \\
\hline PP & 1369745 & 9,87 \\
\hline PSDB & 1314595 & 9,48 \\
\hline PTB & 1158752 & 8,35 \\
\hline PDT & 1127893 & 8,13 \\
\hline DEM & 1103204 & 7,95 \\
\hline PR & 732279 & 5,28 \\
\hline PSB & 492600 & 3,55 \\
\hline PPS & 446115 & 3,22 \\
\hline PSC & 299891 & 2,16 \\
\hline PV & 273193 & 1,97 \\
\hline PC DO B & 269611 & 1,94 \\
\hline PRB & 220765 & 1,59 \\
\hline PMN & 194178 & 1,40 \\
\hline PRP & 190005 & 1,37 \\
\hline PSL & 168622 & 1,22 \\
\hline PTC & 148235 & 1,07 \\
\hline PSDC & 140582 & 1,01 \\
\hline PT DO B & 133975 & 0,97 \\
\hline PHS & 113854 & 0,82 \\
\hline PTN & 100461 & 0,72 \\
\hline PRTB & 93010 & 0,67 \\
\hline PSOL & 40636 & 0,29 \\
\hline PCB & 16001 & 0,12 \\
\hline PSTU & 12549 & 0,09 \\
\hline PCO & 2878 & 100,00 \\
\hline TOTAL & 13874224 & \\
\hline & & \\
\hline
\end{tabular}

Fonte: Tribunal Superior Eleitoral - TSE

Outro importante demonstrativo da força deste partido é o número de prefeituras que ele alcança. Temos como pressuposto que as eleições municipais são a porta de entrada dos partidos no jogo eleitoral. As campanhas/disputas para os cargos estaduais e federais partem das bases municipais, quanto mais apoio os partidos e os candidatos conseguirem neste nível maior a probabilidade de terem êxito nas outras 
esferas. Acreditamos que o PMDB é um dos principais partidos que melhor faz essa leitura, dado a sua sempre relevante votação e conquista de votos neste âmbito.

Tabela 3: Prefeituras eleitas x Partidos

\begin{tabular}{|c|c|c|}
\hline \multicolumn{3}{|c|}{ Todos os Partidos - Outubro / 2008 } \\
\hline Partidos & Prefeitos & $\%$ \\
\hline PMDB & 1203 & 21,68 \\
\hline PSDB & 786 & 14,16 \\
\hline PT & 557 & 10,04 \\
\hline PP & 550 & 9,91 \\
\hline DEM & 496 & 8,94 \\
\hline PTB & 418 & 7,53 \\
\hline PR & 383 & 6,90 \\
\hline PDT & 344 & 6,20 \\
\hline PSB & 311 & 5,60 \\
\hline PPS & 131 & 2,36 \\
\hline PV & 76 & 1,37 \\
\hline PSC & 60 & 1,08 \\
\hline Outros Partidos & 235 & 4,23 \\
\hline TOTAL & 5550 & 100,00 \\
\hline
\end{tabular}

Fonte: Tribunal Superior Eleitoral - TSE

Acreditamos que reside nessa capacidade de manutenção das cadeiras nas esferas municipais a principal explicação para a manutenção do PMDB entre os principais partidos do país. Essa importante ferramenta deve ser colocada junto com a existência dos "puxadores" de voto do partido. O PMDB conseguiu em sua trajetória manter uma grande base territorial de suas lideranças como os grandes puxadores de votos, denominados caciques, por estado.

Essa configuração de elites inclusive é o foco de uma das principais criticas ao partido, ou, o fato gerador de das outras. O PMDB é “conhecido" por ser uma federação partidaria e não um partido. As facções e partes dentro dele são um dos fatores que o impossibilita o lançameno de uma candidatura ao principal cargo em disputa no país, a presidencia. O custo de unificar e apasiguar essas correntes e divergencias internas é considerado alto de mais pelos criticos do partido, o que leva ao partido assumir uma estratégia de buscar maximixar o seu número de cadeiras nos parlamentos e governos subnacionais o que o leva a ser convidado a compor o governo que se instala. Essa estratégia tem se mostrado eficiênde se observarmos os últimos governos nacionais que sempre tiveram o PMDB como parceiro de governança.

$\mathrm{O}$ partido consegue assim manter as suas bases municipais que recebem as verbas negociadas pelos seus representantes nas esferas estaduais e nacionais. Com os recursos conseguidos na "barganha" com as esferas governativas superiores as bases locais são atendidas mantendo assim fieis os cabos eleitorais locais. Assim temos por 
completo o ciclo de "dependencia eleitoral" em que as bases locais são mantidas e garantem as campanhas das proximas eleições. Esquematicamente podemos pensar em algo assim:

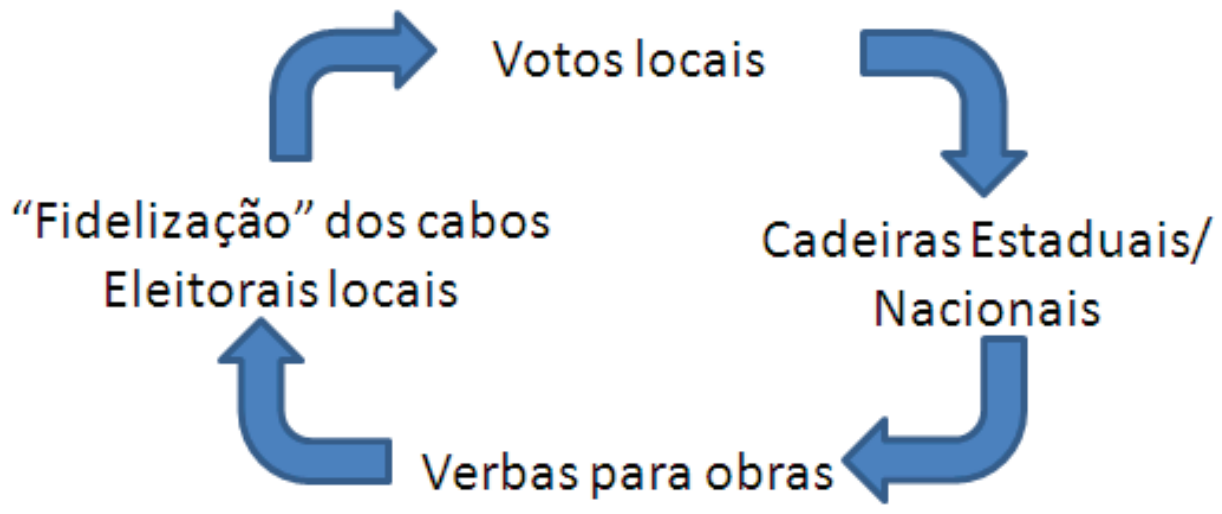

Temos de levar em conta também, a "adaptação" ideologica a "médiana" do eleitorado brasileiro. Ao diluir o seu discurso o PMDB não se vê "comprometido" com nenhum forte ideal, o que lhe possibilita uma maior autonomia de atuação. Em trabalho recente para a cidade de Belo Horizonte (MELO, 2010) demonstra que o pensamento dos eleitores e das lideranças partidarias do PMDB local se mstram bem proximos. O que nós faz levantar a hipotese de que na realidade durante o processo "adaptativo" do partido, o mesmo, mirou no que DOWNS (1999) apontava como o melhor caminho para maximixar a votação.

Outro ponto que temos de levantar é o incentivo proporcionado pela propria legislação eleitoral. O principal ponto de divulgação das campanhas eleitorais no Brasil é o Horario de Propaganda Gratuita Eleitoral (HGPE) no rádio e na televisão, e esse tempo reservado a campanha é distribuido de acordo com o tamanho da bancada que toma posse na legislatura que está se encerrando, ou seja, as maiores bancadas da gestão atual terão o maior tempo de propaganda. O HGPE pode então funcionar como a principal "arma” na manutenção dos candidatos do partido que já possui bancadas significativas, já que permite a estes o maior tempo para se divulgarem e fixarem seu nome durante os 45 dias de campanha.

Todos esses fatores apontados acima, o enraizamento do partido, a dinamica clientelista de manutenção dos cabos eleitorais locais, a "adaptação" ideologica e a distribuição do tempo de propaganda, acarretam na manutenção da força do partido em conversão dos votos em cadeiras. Apenas para reafirmar essa eficiência vamos apresentar na proxima tabela os dados da eficiência ${ }^{6}$ dos partidos em conversão das candidaturas em cadeiras governativas. Essa razão sere para demonstrar que as evidencias apontadas anteriormente, é reafirmada nas eleições de 2010. Os "maiores"

${ }^{6} \mathrm{O}$ calculo é feito ao se dividir o número de candidatos eleitos pelo número de candidatos lançados. 
partidos continuam sendo os mais "eficientes nas conversões de cadeiras, já que são possuidores de maior enraizamento, o maior número de cabos eleitorais e, por conseguinte, o maior tempo de campanha no radio e na televisão, bem como uma maior parcela nos recursos do fundo partidário”.

Tabela 4: Eficiência em conversão de candidatos em cadeiras por partido / 2010

\begin{tabular}{|c|c|c|c|c|}
\hline Partido & Estadual & Federal & Senador & Governador \\
\hline PMDB & 0,21 & 0,23 & 0,83 & 0,54 \\
\hline PSDB & 0,18 & 0,19 & 0,33 & 0,60 \\
\hline PT & 0,17 & 0,26 & 0,52 & 0,60 \\
\hline DEM & 0,15 & 0,23 & 0,17 & 0,50 \\
\hline PR & 0,12 & 0,24 & 0,80 & 0,00 \\
\hline PDT & 0,12 & 0,10 & 0,33 & 0,25 \\
\hline PSB & 0,11 & 0,12 & 0,50 & 0,67 \\
\hline PP & 0,09 & 0,22 & 0,36 & 0,25 \\
\hline PTB & 0,08 & 0,08 & 0,20 & 0,33 \\
\hline PPS & 0,07 & 0,08 & 0,17 & 0,50 \\
\hline PSC & 0,06 & 0,09 & 0,33 & 0,00 \\
\hline PMN & 0,06 & 0,02 & 0,33 & 0,33 \\
\hline PT DO B & 0,05 & 0,03 & 0,00 & 0,00 \\
\hline$\overline{\mathrm{PV}}$ & 0,05 & 0,23 & 0,00 & 0,00 \\
\hline PRB & 0,05 & 0,06 & 1,00 & 0,00 \\
\hline PTN & 0,04 & 0,04 & 0,00 & 0,00 \\
\hline PSL & 0,04 & 0,01 & 0,00 & 0,00 \\
\hline PRP & 0,04 & 0,02 & $\mathrm{~S} / \mathrm{C}$ & 0,00 \\
\hline PSDC & 0,03 & 0,00 & 0,00 & 0,00 \\
\hline PC DO B & 0,03 & 0,13 & 0,11 & 0,00 \\
\hline PRTB & 0,03 & 0,02 & 0,00 & 0,00 \\
\hline PHS & 0,02 & 0,01 & 0,00 & 0,00 \\
\hline PTC & 0,02 & 0,00 & 0,00 & 0,00 \\
\hline PSOL & 0,01 & 0,01 & 0,07 & 0,00 \\
\hline PCB & 0,00 & 0,00 & 0,00 & 0,00 \\
\hline $\mathrm{PCO}$ & 0,00 & 0,00 & 0,00 & 0,00 \\
\hline PSTU & 0,00 & 0,00 & 0,00 & 0,00 \\
\hline
\end{tabular}

Fonte: Tribunal Superior Eleitoral - TSE - Cálculo dos autores

Observando maior detalhe apenas os dados do partido foco deste trabalho temos que ele sempre aparece entre as quatro principais razões nos diferentes cargos calculados. Apresentando a maior eficiência na conversão dos cargos de Deputados Estaduais e Distritais e Senadores, o que demonstra a sua competência inclusive em 
formas eleitorais distintas, majoritária e proporcional. O PMDB consegue como demonstrado na tabela acima um sucesso que o permite ser até a última eleição o maior partido do sistema partidário e se somado as chaves explicativas para a manutenção deste tamanho ele se apresenta como apto a permanecer assim por mais alguns pares de eleições.

\section{CONCLUSÕES}

"Instituições políticas não se fazem por puro ato de vontade, nem da
noite para o dia. Elas requerem o amadurecimento no embate
político, a experiência de enfrentar e vencer desafios, a dimensão
simbólica que só o transcurso do tempo, condição para o
amadurecimento, pode propiciar." (REIS, 2002)

Para se ter uma breve constatação do que é o poder da atual "maquina de votos e cadeiras" que é o PMDB hoje temos de fazer uma analise toda a sua trajetória. Como um partido que foi criado pelo Regime Ditatorial brasileiro se transformou em um fiel da balança do atual sistema político brasileiro? O que devemos destacar é que o partido conseguiu ao longo de sua trajetória uma atual relevância no sistema político brasileiro que pode ser explicado pela sua eficiência em jogar com as regras do sistema. Ao se estudar uma instituição, acredito ser necessário um estudo de sua trajetória, pois essa é capaz de fornecer ao estudioso as ferramentas que vão munir as suas

Durante o percurso do (P) MDB encontramos varias das chaves explicativas que possibilitaram a ele se manter até os dias atuais, apesar das varias fragmentações, do partido e do sistema, como o maior partido do Brasil. Como ressalta Reis (2002) as instituições são forjadas na disputa e no seu amadurecimento com o tempo, e o PMDB soube bem crescer e se adaptar aos empecilhos postos a sua frente.

Partido se mostrou um ser muito bem adaptado às necessidades a ele imposta a ele durante a sua trajetória. Ao estudar a "criatura" que 'melhor' se adaptou ao sistema de conversão de cadeiras e de manutenção no poder do sistema brasileiro, encontramos as chaves explicativas que nos permitirão uma melhor elucidação do processo de conversão de votos em cadeiras.

Acreditamos com esse artigo ter contribuído com as explicações do porque o PMDB se mantem durante tanto tempo como o maior partido do sistema brasileiro e como as suas adaptações são essenciais para essa compreensão. A trajetória percorrida por uma instituição tem muito a contribuir ao analisar o seu presente. 


\section{REFERÊNCIAS BIBLIOGRÁFICAS}

DELGADO, Tarcísio. A história de um rebelde: 40 anos, (1966 - 2006). Fundação Ulysses Guimarães, 2006.

DOWNS, Anthony. Uma teoria Econômica da Democracia. São Paulo, São Paulo: EDUSP, 1999.

FERREIRA, Denise Paiva e RIBEIRO, Pedro Floriano. "O voto e a máquina: as trajetórias de implementação local de PT e (P)MDB em perspectiva comparada”. In__: BAQUERO, M. e CREMONESE, D. Eleições Municipais de 2008: uma análise do comportamento eleitoral brasileiro. Ijuí: Editora Ijuí, 2009.

KINZO, Maria D'Alva. Oposição e Autoritarismo: gênese e trajetória do MDB (1966/1979). São Paulo, SP: Vértice, 1988.

A democratização brasileira: um balanço do processo político desde a transição. São Paulo Perspective. Vol.15, n.4: pp. 3-12, 2001.

LIPJHART, Arendt. (2003). Modelos de Democracia. Rio de Janeiro: Civilização Brasileira. Cap. III - O Modelo consensual de Democracia”, pp. 51-65.

LIPSET, S. and ROKKAN, S. “Cleavage Structure, Party Systems and Voter Alignments". In__: Party System and Voter Alignment. The Free Press, 1967.

MELO, Carlos Ranulfo Felix de. Os partidos e as eleições presidenciais no Brasil. Em Debate, Belo Horizonte, v.2, n.6, p. 6 -11, junho. 2010. $\mathrm{m}$ MELO, Paulo Victor Teixeira P. A Lei da Disparidade Ideologica Curvilinear dos Partidos Politicos: O PMDB de Belo Horizonte. Monografia de conclusão de curso. UFMG, 2010.

NICOLAU, Jairo. Disponível em: <http://jaironicolau.iuperj.br>. Último acesso em 07 de Junho de 2010.

PANEBIANCO, Ângelo. Modelos de Partido. São Paulo, São Paulo: Martins Fontes, 2005 .

REIS, Fábio Wanderley. O Tempo Presente: do MDB a FHC. Belo Horizonte, MG: Editora UFMG, 2002.

SARTORI, Giovanni. Partidos e Sistemas Partidários. Brasília, DF: UNB, 1976.

TSE. Tribunal Superior Eleitoral. Disponível em: <http://www.tse.gov.br>. Último acesso em 07 de junho de 2010. 